\title{
The Religious Observance Of Ramadan And Prosocial Behavior
}

\author{
Ernan E. Haruvy *† \\ University of Texas at Dallas \\ Christos A. Ioannou $\ddagger$ \\ Farnoush Golshirazi ${ }^{\S}$ \\ University of Southampton \\ University of Oxford
}

This draft: May 20, 2017

\begin{abstract}
We investigate experimentally the impact on prosocial behavior of the religious observance of Ramadan. Our sample consists of male factory workers in a manufacturing facility in a Muslim country. In our between-subjects' design, each worker is asked to allocate an amount of money between himself and a stranger. Specifically, we examine behavior of observants and non-observants before and after the daily break of the Ramadan fast. We also examine behavior outside of Ramadan, where we treat alimentary abstention as akin to a long fasting period. We hypothesize and confirm that outside Ramadan, decision makers who abstain from any alimentary intake transfer less money to recipients relative to decision makers who do not abstain. Strikingly, this effect is reversed during the month of Ramadan. Specifically, observant workers who are in the midst of their Ramadan fast are far more generous to recipients than workers who have had their evening meal. Interestingly, observant and non-observant workers after the daily break of the Ramadan fast and workers outside Ramadan that consumed aliments make statistically similar transfers. Our findings suggest that it is the interaction between alimentary abstention and religious observance that amplifies prosocial behavior during Ramadan, where fasting is part of the ritual.
\end{abstract}

JEL: C91, C93, C72

Keywords: Ramadan, Dictator Game, Religiosity, Prosocial Behavior

\footnotetext{
* The paper has benefited greatly from the comments of Shai Danziger, Raymond O'Brien, Alexis Antoniades, Manos Mentzakis, Carmine Ornaghi, Miltos Makris, Abbas Zabihzadeh, Mohammad Reza Abedi, Jean-Yves Pitarakis, Hamid Taher Neshat Doost and Mohammad Ali Mazaheri. Finally, we are indebted to the editor, Martin Gervais, and two anonymous referees for their insightful comments, which significantly improved the paper. The research was supported by research funds from the Strategic Research Development Fund of the University of Southampton and the University of Texas at Dallas. The usual disclaimer applies.

${ }^{\dagger}$ Jindal School of Management, Richardson, TX 75083, USA.

${ }^{\ddagger}$ Department of Economics, Southampton, SO17 1BJ, UK.

${ }^{\S}$ Department of Economics, Oxford, OX1 3UQ, UK.
} 


\section{Introduction}

Does alimentary (henceforth, aliments refer to food and fluids) intake amplify prosocial behavior? Recent physiological research indicates that self-control, which is necessary for prosocial acts, requires glucose intake (see Gailliot, Baumeister, DeWall, Maner, Plant, Tice, Brewer, and Schmeichel (2007), Gailliot and Baumeister (2007), and Gailliot (2015)). Glucose-depleted individuals may profess greater support for social welfare, but when incentivized they do not seem to behave in a prosocial manner. Specifically, when these individuals are asked to redistribute an endowment between themselves and a recipient, higher blood glucose levels are shown to lead to greater giving (Aarøe and Petersen (2013)). Perhaps, the most striking field evidence of the association between alimentary intake and prosocial behavior is from a study on decisions by Israeli judges (Danziger, Levav, and Avnaim-Pesso (2011)). In the study, Israeli judges are shown more likely to grant a parole or a parolee's request after a meal break when controlling for the characteristics of the cases examined.

Given the evidence that alimentary intake is associated with higher prosocial giving, it might seem strange that major religious festivities integrate fasting with giving. However, the ritual of fasting may serve other goals aside from prosocial giving. For instance, it may serve to strengthen the bond between the individual and God or between the individual and the religion itself. These aspects of religiosity trigger different effects on socioeconomic outcomes (see Barro and McCleary (2003), McCleary and Barro (2006), and Carpantier and Litina (2014)), which complicate both conceptually and empirically the task of assessing and identifying their impact on economic decisions. ${ }^{1}$

In this study, we propose a controlled between-subjects' experiment to investigate the impact on prosocial behavior of the religious observance of Ramadan, where fasting is part of the ritual. Ramadan is the ninth month of the Islamic lunar calendar and is considered sacred as it is the month in which Prophet Muhammad first received revelations. The month lasts 29-30 days based on the visual sightings of the crescent moon. Muslims are called upon to use this month to re-evaluate their lives in light of the Islamic guidance. Specifically, the observance of Ramadan dictates a well-defined rule of behavior whereby followers all over the world engage in fasting (Sawm). Sawm is one of the five Pillars of Islam. The five Pillars are understood to be obligatory for all Muslim believers and form the foundation of Muslim life. The other four central tenets consist of: (i) declaring there is no god

\footnotetext{
${ }^{1}$ Campante and Yanagizawa-Drott (2015) identify three ways in which religious practices constrain believers and thereby affect economic outcomes. First, they require a tradeoff between time and resources that are then unavailable for production. Second, they can affect directly productivity either by limiting social interactions with non-believers or by imposing dietary restrictions. Third, they may shape beliefs and values that affect economic decisions.
} 
except God and Muhammad is God's Messenger (Shahadah), (ii) ritual prayer five times a day (Salat), (iii) giving to the poor and needy (Zakat), and (iv) pilgrimage to Mecca (Hajj). Sawm encompasses abstention from any consumption of aliments from dawn to sunset during the entire month. Naturally, this entails physiological consequences. Medical literature has consistently found body weight loss, significant metabolic changes and symptoms, such as irritability, headaches, sleep deprivation and lassitude (see, for example, Ziaee, Razaei, Ahmadinejad, Shaikh, Yousefi, Yarmohammadi, Bozorgi, and Behjati (2006)). Furthermore, studies have documented significant prevalence of individuals reporting tiredness and unwillingness to work as well as reduced levels of activity and concentration ability (see, for instance, Karaağaoğlu and Yücecan (2000)). To date, however, very few economic studies have been conducted in Islamic countries in the context of religious observances, such as the month of Ramadan. ${ }^{2}$

Our unique sample consists of male workers in a manufacturing factory in a Muslim country. We employ a standard Dictator decision task (Forsythe, Horowitz, Savin, and Sefton (1994)) to assess prosocial behavior as is often done in the literature (see, for example, Aarøe and Petersen (2013)). Specifically, the decision maker (the 'dictator') is provided with a monetary endowment. He is then asked to allocate the endowment between himself and a passive (outside) recipient with the understanding that the allocation will be implemented immediately. ${ }^{3}$ We examine behavior of observants and non-observants before and after the daily break of the Ramadan fast, which allows us to associate fasting and prosocial behavior. We also examine the behavior of the factory workers outside Ramadan, where we do not have the daily break of the fast as the natural time separation. Instead, we treat alimentary abstention as akin to a long fasting period.

In line with existing literature, we confirm that, outside Ramadan, decision makers who abstained from any alimentary intake transfer less money to recipients relative to decision makers who did not abstain. Furthermore, we test the hypothesis that, in the midst of the Ramadan fast, abstention from any consumption of food and fluids along with the spirit of the religious observance will make religious principles more salient, and Ramadan-observant workers will be far more generous to recipients than those who have had their evening meal. Indeed, observant workers, in the midst of their fast, give significantly more to recipients. Interestingly, observant workers during Ramadan, who have had their evening meal, and

\footnotetext{
${ }^{2}$ Some notable exceptions are the studies of Clingingsmith, Khwaja, and Kremer (2009) and Campante and Yanagizawa-Drott (2015).

${ }^{3}$ This setup has been used extensively in the literature to test the basic economic premise of individuals behaving in their own self-interest. Experimental results, contrary to this premise, have indicated that only a minority of dictators keep the entire endowment to themselves (Forsythe, Horowitz, Savin, and Sefton (1994)). Researchers (see, for instance, Andreoni and Miller (2002)) have attributed this behavior to prosocial preferences.
} 
workers outside Ramadan, who did not abstain from any food and fluids intake make statistically similar transfers. These findings suggest that it is the interaction between alimentary abstention and religious observance that amplifies prosocial behavior during Ramadan, where fasting is part of the ritual.

The layout of this paper adheres to the following plan. In Section 2, we describe the experimental design, and in Section 3, we formulate our general hypotheses. In Section 4, we report the important findings, and in Section 5, we discuss them. Finally, in Section 6, we offer concluding remarks.

\section{Experimental Methodology}

The experiments were run in a manufacturing facility. In Figure 1, we display the age and monthly wage distribution of the factory's labor force at the time of the experiments. At that time, the factory had 881 workers where almost $90 \%$ were men. Workers work in the factory in 12-hour shifts. There are two types of shifts: the day shift that starts at 6:30am and the night shift that starts at $6: 30 \mathrm{pm}$. Typically, two meals are served in the factory: a lunch in the day shift, which takes place around 1:30pm, and a dinner in the night shift, which takes place around 8:30pm. In addition, a snack in lieu of a breakfast is served to the day-shift workers around 10:00am. Finally, from 10:00am until 6:00pm a canteen operates that sells various nourishments. During the month of Ramadan, no snack or lunch is served and the dinner takes place a few minutes after the sunset. Furthermore, people not observing the Ramadan fast must use the cafeteria space to eat and drink in order not to provoke the individuals that observe the fast. The canteen is throughout the month of Ramadan closed.

Our objective in this study is to examine the impact on prosocial behavior of the religious observance of Ramadan, where fasting is part of the ritual. In the experimental design, we focused on three dimensions. The first dimension is whether the decision maker

abstained from any intake of aliments. The second dimension is whether the calendar date of the experiment coincided with the month of Ramadan. The third dimension is whether the participant was a Ramadan-observant. We thus examined behavior of observants and non-observants before and after the daily break of the Ramadan fast as well as outside of Ramadan, where we treated alimentary abstention as akin to a long fasting period.

All sessions took place in the cafeteria at the factory premises. On the days of the experiments, both the cafeteria and the canteen were kept closed to enable the experimenters to arrange the space appropriately. Our between-subjects' experimental design consisted of three sessions. In each session, we invited 80 participants. Two sessions (one night session 
Figure 1: Age \& Monthly Wage Distribution of the Factory's Labor Force
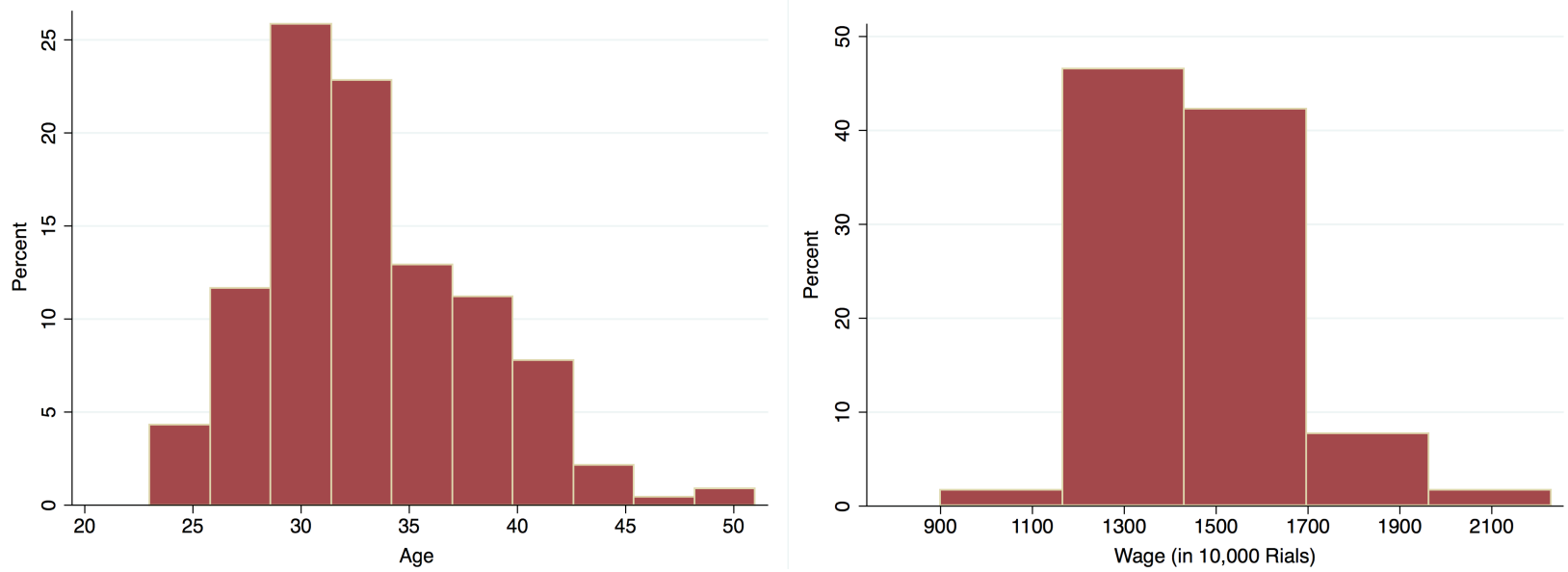

Notes: This information was provided by the management of the factory. Note that 1,000,000 Rials is around $\$ 31.50$.

and one day session) took place during the month of Ramadan, which started on June $28^{\text {th }}$ of 2014 and ended on July $27^{\text {th }}$ of 2014. Specifically, the night session was conducted on July $14^{\text {th }}, 2014$ at 10:30pm with night-shift workers, and the day session was conducted on July $16^{\text {th }}, 2014$ at 1:00pm with day-shift workers. One more day session with day-shift workers was conducted outside of Ramadan on March $5^{\text {th }}, 2015$ at 1:30pm. ${ }^{4}$ All experimental sessions were paper-and-pencil. Employees were allowed to participate in only one session. Any concerns for spillover effects across sessions were mitigated by the calendar distance between the two day sessions, and by the management's reassurance that day-shift workers and nightshift workers very rarely overlap or interact at the factory premises. The characteristics of the experimental sessions are shown in Table 1. A total of 8 participants were excluded from the analysis as they did not fit the definitional requirements of abstention and non-abstention imposed by the experimenters (see our terminology on p. 6). The age and monthly wage distribution of the participants by group (the group classification is provided in Subsection 4.1) is provided in the Appendix.

Initially, participants were offered 50,000 Rials (around \$1.60) for their participation in the experiment. This amount was paid to them at the very end of the experiment. Participants were instructed that the session consisted of two parts to be described at the appropriate time. In the first part, they were presented with a single shot, Dictator task

\footnotetext{
${ }^{4}$ This date was placed in-between the religious festivity of Eid Milad un Nabi that was celebrated on January $8^{\text {th }}, 2015$ and the religious festivity of Lailat al Miraj that was celebrated on May $13^{\text {th }}, 2015$.
} 
Table 1: Characteristics of the Experimental Sessions

\begin{tabular}{cccccc}
\hline \hline Date & Time & $\begin{array}{c}\text { \# of } \\
\text { participants }\end{array}$ & $\begin{array}{c}\text { \# of } \\
\text { Ramadan } \\
\text { observants }\end{array}$ & $\begin{array}{c}\text { Took place } \\
\text { during } \\
\text { Ramadan? }\end{array}$ & $\begin{array}{c}\text { \# who } \\
\text { abstained from } \\
\text { aliments }\end{array}$ \\
\hline July 14, 2014 & $10: 30 \mathrm{pm}$ & 80 & 47 & Yes & 0 \\
July 16, 2014 & $1: 00 \mathrm{pm}$ & 77 & 52 & Yes & 52 \\
March 5, 2015 & $1: 30 \mathrm{pm}$ & 75 & 75 & No & 28 \\
\hline
\end{tabular}

Notes: In the first two columns, we provide information on the calendar date and time of the sessions. In the third column, we provide the total number of participants. The fourth column indicates the number of participants who observed the Ramadan fast as self-reported in the questionnaire. The fifth column indicates whether the session took place during the month of Ramadan or not. The last column indicates the number of participants who abstained from any consumption of aliments in the last seven hours as self-reported in the questionnaire.

and were all in the role of dictator. ${ }^{5}$ Specifically, dictators were given an envelope, which contained 10 notes of 10,000 Rials each, for a total of 100,000 Rials. They were then asked to decide how many Rials out of the 100,000 Rials they would like to keep, while noting that the remaining amount would be transferred to a person outside of the factory. ${ }^{6}$ All dictators were informed that the outside recipient would not be given any identifying information about them and that all information was completely anonymous. The recipients of the money were women who are under the supervision of the Seddigin Charity Foundation. The foundation is dedicated to feeding hungry women. Neither the recipients' gender nor the name of the foundation was disclosed to the decision makers. Dictators had to place the amount to be transferred inside the envelope. The amount that was not transferred was theirs to keep. The envelopes were collected at the end of the session and the amount in the envelopes was recorded. In the second part, participants were asked to complete a questionnaire. Two questions asked participants to report on their religion (all participants self-reported to be Muslims), and on whether they observed the Ramadan fast. ${ }^{7}$ Further

\footnotetext{
${ }^{5}$ In a series of recent publications in economics, caution was urged in drawing inferences on the Dictator games when mapping laboratory evidence to the field (List (2007), Bardsley (2008), Zizzo (2010), Zizzo and Fleming (2011), and Zizzo (2013)). The aforementioned studies posit that dictators' behavior could instead be driven by experimenter demand effects. Moreover, the presence of experimenter demand effects could be amplified as a result of different cues (Burnham (2003), Haley and Fessler (2005), Brañas-Garza (2006), Brañas-Garza (2007), and Koch and Normann (2008)). While experimenter demand effects may have an impact on subjects' decisions, any such effects should be constant across sessions; consequently, they merit no real concern to the interpretation of our results.

${ }^{6}$ We felt compelled to impose these (non-standard) assumptions to eliminate possible confounding effects that could arise due to expectations of generalized reciprocity (Yamagishi and Kiyonari (2000)).

${ }^{7}$ Socially, there is no taboo in admitting lapses in fasting, for medical, travel or other reasons during
} 
questions were posed to determine whether participants had consumed any food or fluids at all in the last seven hours, and for those who did consume, what they had consumed and how many hours had elapsed since their very last consumption. These questions were placed to enable the experimenters to classify abstaining and non-abstaining participants appropriately. For instance, a participant who consumed food in the last seven hours, but had no nourishments whatsoever in the last 3 hours could potentially have depleted his glucose levels. In contrast, a participant who consumed food within the hour, would still have rich levels of glucose. To avoid confusion, our terminology as to how we interpret abstention and how we define non-abstention is presented next. Henceforth, we define those who abstained from any consumption of aliments as those who did not have anything to eat or drink (not even a sip of water) for at least seven hours, and we define those who did not abstain from any consumption of aliments as those who had something to eat or drink (even a sip of water) in the last two hours. ${ }^{8}$ A total of 8 participants had something to eat or drink in the last seven hours, but did not have anything to eat or drink for more than two hours and were thus taken out of the sample. ${ }^{9}$ The experimental instructions are provided in the Appendix.

To ensure that samples were randomly drawn and that the same experimental conditions were maintained across sessions we had to make the following design choices. As stated earlier, the night session during Ramadan took place at 10:30pm. At that time very few women work at the factory. We were thus compelled to eliminate women from the experimental sessions altogether to safeguard against a sampling bias. Though we precluded female participants, the recruitment of male participants was otherwise done randomly. Furthermore, to maintain comparability across sessions, we had to ensure the same number of hours of alimentary abstention during the day experiments. We were thus led to conduct the day experiments at different times. During Ramadan, the experiment took place at 1:00pm,

Ramadan. Hence, we had no difficulty in getting a large minority portion of the sample admitting to not fasting during Ramadan without fear or stigma. This was not the case with participants outside of Ramadan. Placing the question more broadly did not sit well with respondents; hence, all participants reported observing the Ramadan fast.

${ }^{8}$ In other words, participants who said 'Yes' to Q5 in the questionnaire and either said 'Less than one hour' or 'Between 1 and 2 hours' since their last consumption in Q7 were labelled as 'did not abstain' from any alimentary intake.

${ }^{9}$ The 3 of the 8 participants took part in the July 16, 2014 session. All three participants were nonRamadan observant: the 2 participants who reported between 3 and 4 hours having elapsed since their last consumption transferred 3 and 5 notes, respectively, to the recipients, whereas the other participant who reported more than 4 hours transferred 5 notes to the recipient. The other 5 participants took part in the March 5, 2015 session, and all self-reported to be Ramadan observant: the 2 participants who reported between 2 and 3 hours having elapsed since their last consumption transferred 3 and 5 notes, respectively, to recipients, whereas the other 3 participants who reported more than 4 hours transferred 4,5 and 5 notes, respectively, to recipients. 
whereas outside Ramadan the experiment took place at 1:30pm. On July $16^{\text {th }}$, 2014 the sunrise took place at 6:00am. Given that the experiment took place at 1:00pm, it is safe to assume that (Ramadan-observant) participants had been fasting for at least seven hours. To have meaningful comparison to the Ramadan day session, we therefore had to conduct the experiment of March $5^{\text {th }}, 2015$ at 1:30pm right before lunch in order to ensure an alimentary abstention of, also, at least seven hours (recall the day shift starts at 6:30am). To secure a large number of participants abstaining from any intake of aliments, on that day, we forewent serving the snack at 10:00am and kept the canteen closed for the entire day. Additionally, by announcing and keeping the canteen closed for the entire day, we ensured that money had no immediate value in any of the sessions (recall that during Ramadan the canteen is kept closed). Nevertheless, some workers still consumed (home-made) aliments. ${ }^{10}$ Workers who had consumed aliments within the last two hours on that day were compared to the night-shift workers of the Ramadan session that took place at 10:30pm. The sunset on July $14^{t h}, 2014$ was at 8:21pm. The night shift workers had their dinner right after the sunset. This ensures a two-hour window to consume aliments during Ramadan, which is comparable to the window allowed outside of Ramadan.

\section{General Hypotheses}

We formulate three general hypotheses. The first hypothesis examines the differences in transfer, outside of Ramadan, when manipulating dictators' alimentary abstention. Specifically, we hypothesize that, outside Ramadan, abstaining dictators will transfer less money to recipients relative to dictators who do not abstain. Existing psysiological literature establishes that individuals with higher blood glucose levels are more giving than individuals with depleted glucose levels (Aarøe and Petersen (2013)). Along the same lines, Harel and Kogut (2015) indicate that people tend to be more generous when satisfied than when actively experiencing a visceral need, such as hunger.

Hypothesis 1 Outside Ramadan, abstaining dictators transfer less money to recipients relative to dictators who do not abstain.

The second hypothesis aims to investigate the effect on dictators' transfers, during Ramadan, of the interaction between alimentary abstention and the religious observance of Ramadan, where fasting is part of the ritual. During Ramadan, we hypothesize that the combination of the two will make religious principles more salient, and thus observant dicta-

\footnotetext{
${ }^{10}$ In the questionnaire, these workers self-reported to have eaten in the last seven hours food items, such as one or two slices of toast, oranges, biscuits, bread and cheese, and to have drunk mostly tea and water.
} 
tors in the midst of their fast will increase significantly their transfers relative to observant dictators who have had their evening meal. Indeed, existing experimental literature finds evidence that priming religion causes subjects to identify more with their religion and affects their decisions. Lambarraa and Riener (2012), for instance, manipulate the saliency of Islamic values in their field experiments in Morocco to investigate the effect on charitable giving. The authors use the Arabic language (in lieu of the French language) to prime participants' religiosity, and find that donations increase significantly.

Hypothesis 2 In Ramadan, observant dictators in the midst of their fast transfer more money to recipients relative to observant dictators who have had their evening meal.

The third hypothesis serves as a direct test of the impact of the religious observance of Ramadan on dictators' transfers. We conjecture that the observance of Ramadan is salient enough to cause dictators who have had their evening meal to transfer more to recipients relative to dictators, outside of Ramadan, who do not abstain.

Hypothesis 3 Observant dictators who have had their evening meal in Ramadan transfer more money to recipients relative to dictators, outside of Ramadan, who do not abstain.

\section{Results}

The three hypotheses are formally tested next. Each hypothesis is matched with the corresponding result; that is, result $i$ is a report on the test of hypothesis $i$.

\subsection{Descriptive Statistics}

We first report descriptive statistics on the raw experimental data. Based on the calendar date and time and the participants' responses in the questionnaire, participants were classified into six groups: four Ramadan groups and two outside-of-Ramadan groups. The four groups during Ramadan are: (i) observant, post-dinner, (ii) non-observant, post-dinner, (iii) observant, mid-fast, and (iv) non-observant, mid-fast. The two groups outside of Ramadan are: (v) abstained from any aliments, and (vi) did not abstain from any aliments. In Table 2 , we report the frequency and percentage for each monetary transfer of the decision makers by group. To simplify the exposition, the transfers are displayed in terms of the number of notes out of a total of 10 notes. The histograms are displayed in Figure 2. Note that the mean payoff can be calculated by subtracting the mean transfer from the endowment and adding up the show-up fee. 
Table 2: Summary Statistics

\begin{tabular}{|c|c|c|c|c|c|c|c|c|}
\hline \multirow{4}{*}{$\begin{array}{l}\text { Panel A } \\
\text { Transfer }\end{array}$} & \multicolumn{8}{|c|}{ In Ramadan } \\
\hline & \multicolumn{4}{|c|}{ Observant } & \multicolumn{4}{|c|}{ Non-Observant } \\
\hline & \multicolumn{2}{|c|}{ Mid-Fast } & \multicolumn{2}{|c|}{ Post-Dinner } & \multicolumn{2}{|c|}{ Mid-Fast } & \multicolumn{2}{|c|}{ Post-Dinner } \\
\hline & Freq. & Percent & Freq. & Percent & Freq. & Percent & Freq. & Percent \\
\hline 0 & 3 & 5.77 & 5 & 10.64 & 3 & 12.00 & 0 & 0.00 \\
\hline 1 & 1 & 1.92 & 0 & 0.00 & 1 & 4.00 & 1 & 3.03 \\
\hline 2 & 4 & 7.69 & 7 & 14.89 & 8 & 32.00 & 11 & 33.33 \\
\hline 3 & 4 & 7.69 & 4 & 8.51 & 1 & 4.00 & 7 & 21.21 \\
\hline 4 & 4 & 7.69 & 3 & 6.38 & 0 & 0.00 & 0 & 0.00 \\
\hline 5 & 11 & 21.15 & 20 & 42.55 & 7 & 28.00 & 11 & 33.33 \\
\hline 6 & 2 & 3.85 & 0 & 0.00 & 0 & 0.00 & 0 & 0.00 \\
\hline 7 & 0 & 0.00 & 0 & 0.00 & 0 & 0.00 & 0 & 0.00 \\
\hline 8 & 2 & 3.85 & 0 & 0.00 & 0 & 0.00 & 0 & 0.00 \\
\hline 9 & 0 & 0.00 & 0 & 0.00 & 0 & 0.00 & 1 & 3.03 \\
\hline 10 & 21 & 40.38 & 8 & 17.02 & 5 & 20.00 & 2 & 6.06 \\
\hline Obs. & 52 & & 47 & & 25 & & 33 & \\
\hline Mean & & 6.35 & & 4.64 & & 4.20 & & 3.88 \\
\hline St. Dev. & & 3.42 & & 2.95 & & 3.39 & & 2.29 \\
\hline
\end{tabular}

Panel B

Outside of Ramadan

Abstained Did Not Abstain

Transfer Freq. Percent Freq. Percent

\begin{tabular}{ccccc}
\hline 0 & 4 & 14.29 & 7 & 14.89 \\
1 & 4 & 14.29 & 1 & 2.13 \\
2 & 6 & 21.43 & 6 & 12.77 \\
3 & 2 & 7.14 & 3 & 6.38 \\
4 & 1 & 3.57 & 1 & 2.13 \\
5 & 10 & 35.71 & 18 & 38.30 \\
6 & 0 & 0.00 & 3 & 6.38 \\
7 & 0 & 0.00 & 1 & 2.13 \\
8 & 0 & 0.00 & 0 & 0.00 \\
9 & 0 & 0.00 & 0 & 0.00 \\
10 & 1 & 3.57 & 7 & 14.89 \\
\hline Obs. & 28 & & 47 & \\
Mean & & 3.07 & & 4.49 \\
St. Dev. & & 2.34 & & 3.05
\end{tabular}

Notes: In the two panels, we report the frequency and percentage for each monetary transfer of the decision makers by group. 
Figure 2: Transfers By GrouP
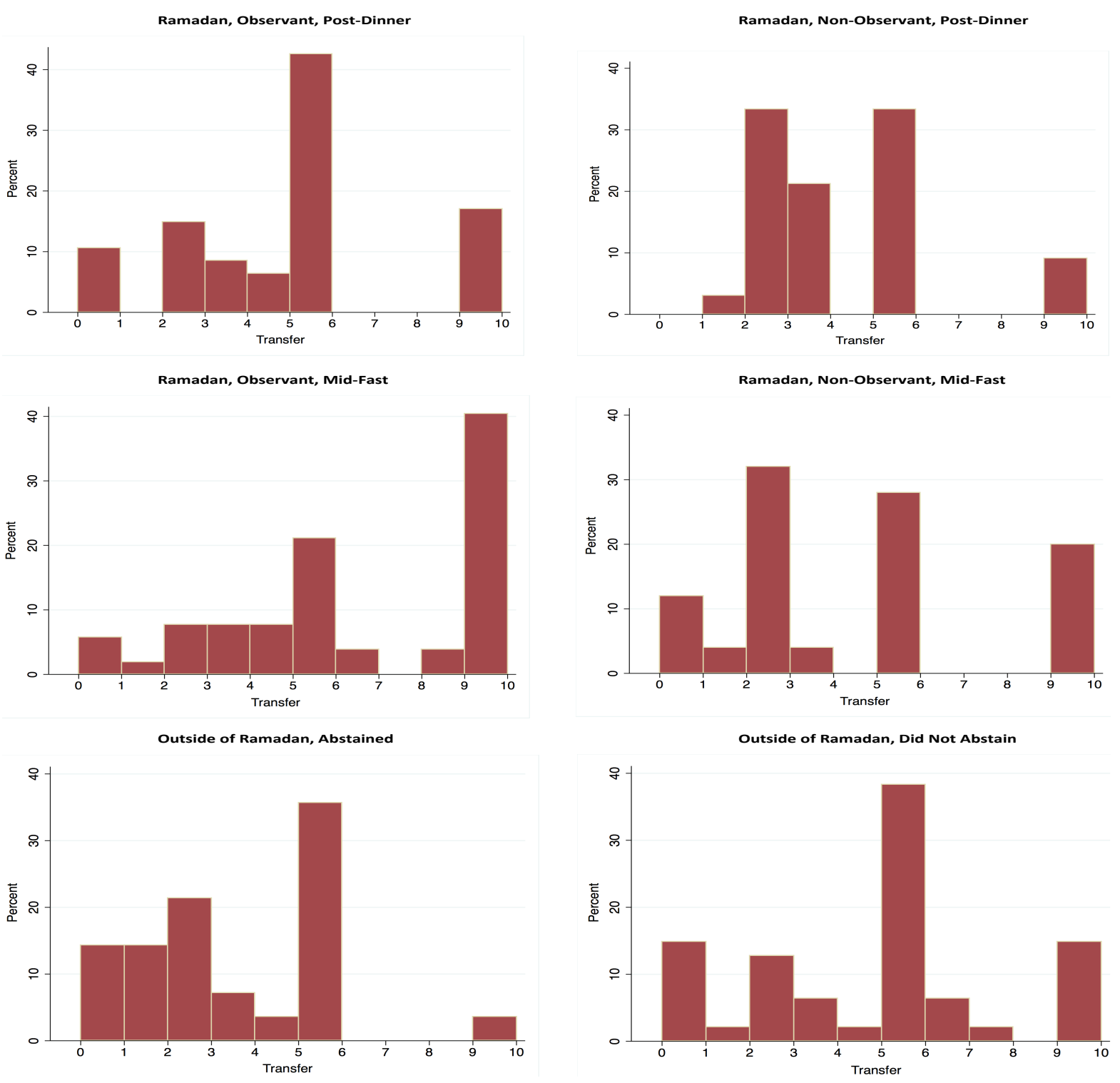

By the strictest economic principle of self-serving economic agents, an individual should transfer nothing to an anonymous recipient. That principle we can reject outright. Even in our most extreme group, the abstaining dictators outside of Ramadan, the mean is 3.07 notes. Next, relaxing the self-serving principle, outside Ramadan, abstaining dictators are predicted to transfer fewer notes to recipients than non-abstaining dictators. Indeed, those who abstained from any aliments transferred on average 3.07 notes to recipients, whereas dictators who did not abstain transferred 4.49 notes. During Ramadan, for the observant participants, the trend is reversed: dictators in the mid-fast session gave on average 6.35 notes to recipients in contrast to dictators in the post-dinner session who transferred 4.64 notes (i.e. the difference in giving is 1.71 notes). 


\subsection{Analysis}

We perform next statistical analysis to investigate the effect of the treated variables on the dictators' transfers. First, we conduct a number of regressions on transfer. The first three models are Tobit regressions where observations are left censored at 0 and right censored at 10. The fourth model is an OLS regression. As our base in the regressions, we take the transfer of the non-abstaining dictators outside of Ramadan. The estimates of the four models are displayed in Table 3. Second, we present the $p$-values of the pairwise comparisons of the distribution of transfers using the Kruskall-Wallis Rank test (see the analysis of Feltovich (2003) for the appropriateness of the latter test), where the $H_{0}$ states that there are no differences across the selected groups. The results of the Kruskall-Wallis Rank test with ties are displayed in Table 4. In Panel A of Table 4, we report the comparisons in the transfers between abstaining and non-abstaining dictators outside of Ramadan, mid-fast and post-dinner dictators who are observant in Ramadan, and mid-fast and post-dinner dictators who are non-observant in Ramadan. In Panel B of Table 4, we investigate the differences in transfer across non-abstaining dictators outside of Ramadan, post-dinner dictators who are observant in Ramadan, and post-dinner dictators who are non-observant in Ramadan. ${ }^{11}$

The first hypothesis examines the differences in transfer, outside of Ramadan, when manipulating dictators' alimentary abstention. The coefficient of the variable 'Abstained' in Table 3 is negative and significant in all regressions. Therefore, we can confirm that, outside Ramadan, decision makers who abstained from any consumption of aliments transfer less money to recipients relative to decision makers who did not abstain. This is also reflected in Panel A of Table 4 where the $H_{0}$ is rejected at the $5 \%$ level. In line with the findings of Harel and Kogut (2015), our first main result is formalized as follows.

Result 1 Outside Ramadan, abstaining dictators transfer significantly less money to recipients relative to non-abstaining dictators.

The second hypothesis aims to investigate the effect on dictators' transfers, during Ramadan, of the interaction between alimentary abstention and the religious observance of Ramadan, where fasting is part of the ritual. The estimates of the variable 'Mid-Fast $\times$ Observant $\times$ Ramadan' in Table 3 are positive, significant and large enough to reverse the trend observed outside of Ramadan. The comparison with non-observant participants at Panel A of Table 4 rules out a time-of-the-day effect (afternoon vs. night-time). These findings culminate in our second main result.

\footnotetext{
${ }^{11}$ The median tests performed on the equality of the medians confirm the stated results.
} 
Table 3: Regressions on Transfer

\begin{tabular}{|c|c|c|c|c|}
\hline Variables & (i) & (ii) & (iii) & (iv) \\
\hline Intercept & $\begin{array}{l}5.12^{* * * *} \\
(0.30)\end{array}$ & $\begin{array}{l}4.46^{* * *} \\
(0.62)\end{array}$ & $\begin{array}{l}4.46^{* * *} \\
(0.60)\end{array}$ & $\begin{array}{c}1.40 \\
(1.43)\end{array}$ \\
\hline Abstained & $\begin{array}{l}-2.34^{* * * *} \\
(0.85)\end{array}$ & $\begin{array}{l}-1.68^{*} \\
(1.01)\end{array}$ & $\begin{array}{l}-1.67^{*} \\
(0.97)\end{array}$ & $\begin{array}{l}-1.24^{*} \\
(0.71)\end{array}$ \\
\hline Ramadan & & $\begin{array}{c}0.85 \\
(0.71)\end{array}$ & $\begin{array}{l}-0.15 \\
(1.01)\end{array}$ & $\begin{array}{l}-0.04 \\
(0.74)\end{array}$ \\
\hline Mid-Fast $\times$ Observant $\times$ Ramadan & & & $\begin{array}{l}2.89^{* * *} \\
(1.01)\end{array}$ & $\begin{array}{l}2.07^{* * *} \\
(0.72)\end{array}$ \\
\hline Post-Dinner $\times$ Ramadan & & & $\begin{array}{l}-0.33 \\
(1.07)\end{array}$ & $\begin{array}{l}-0.51 \\
(0.79)\end{array}$ \\
\hline Post-Dinner $\times$ Observant $\times$ Ramadan & & & $\begin{array}{c}0.76 \\
(0.91)\end{array}$ & $\begin{array}{l}0.79 \\
(0.67)\end{array}$ \\
\hline Age & & & & $\begin{array}{l}0.09^{* *} \\
(0.04)\end{array}$ \\
\hline Observations & & & & \\
\hline
\end{tabular}

Notes: A dictator's transfer is the dependent variable. The first three models are Tobit regressions. 22 observations were left censored at 0 and 44 observations were right censored at 10 . The fourth model is an OLS regression. As a base, we used non-abstaining dictators outside of Ramadan. 'Abstained' is a dummy variable that takes the value of 1 if the dictator outside Ramadan abstained from any intake of aliments and 0 otherwise, 'Ramadan' is a dummy variable that takes the value of 1 if the dictator is in Ramadan and 0 otherwise, 'Mid-Fast $\times$ Observant $\times$ Ramadan' is a dummy variable that takes the value of 1 if the dictator is an observant who is in the midst of his fast in Ramadan and 0 otherwise, 'Post-Dinner $\times$ Ramadan' is a dummy variable that takes the value of 1 if the dictator had his evening meal in Ramadan and 0 otherwise, and 'Post-Dinner $\times$ Observant $\times$ Ramadan' is a dummy variable that takes the value of 1 if the dictator is an observant who had his evening meal in Ramadan and 0 otherwise. The variable 'Age' corresponds to the age of the dictator. All standard errors are reported in parentheses. ${ }^{*}$ Significant at the $10 \%$ level $* *$ Significant at the $5 \%$ level *** Significant at the $1 \%$ level.

Result 2 In Ramadan, post-dinner, observant dictators transfer significantly less money to recipients relative to observant dictators in the midst of their fast. On the other hand, the difference in behavior between non-observant, mid-fast dictators and non-observant, postdinner dictators is not significant.

The third hypothesis tests the direct impact of the religious observance of Ramadan on dictators' transfers. Table 3 indicates, contrary to our conjecture in Section 3, that Ramadan by itself, without the interaction with alimentary abstention, has no significant effect on transfer despite the fact that all respondents identified themselves as practicing Muslims and an important tenet of Muslim life is giving. A close look at Panel B in Table 


\section{Table 4: Kruskall-Wallis RAnK Tests on Transfer}

\section{Panel A}

Alternative hypothesis:

$$
\frac{\text { transfer }_{i} \neq \text { transfer }_{j}}{p \text {-values }}
$$

Outside of Ramadan

Abstained vs. Did Not Abstain

In Ramadan

Observant

Mid-Fast vs. Post-Dinner

Non-Observant

Mid-Fast vs. Post-Dinner

0.83

Panel B

Alternative hypothesis:

$$
\frac{\text { transfer }_{i} \neq \text { transfer }_{j}}{p \text {-values }}
$$

Outside of Ramadan, Did Not Abstain vs.

In Ramadan, Non-Observant, Post-Dinner

Outside of Ramadan, Did Not Abstain vs.

In Ramadan, Observant, Post-Dinner

In Ramadan, Observant, Post-Dinner vs.

In Ramadan, Non-Observant, Post-Dinner

Notes: We utilize the Kruskall-Wallis Rank tests (with ties) to determine any differences $(i \neq j)$ in the transfer across the selected groups. In Panel A, we report the $p$-values of the comparison in the transfers between abstaining and non-abstaining participants outside of Ramadan, mid-fast and post-dinner dictators who are observant in Ramadan, and mid-fast and post-dinner dictators who are non-observant in Ramadan. In Panel B, we report the $p$-values of the comparison in the transfers across non-abstaining dictators outside of Ramadan, post-dinner dictators who are observant in Ramadan, and post-dinner dictators who are nonobservant in Ramadan.

4 reveals that the amount given by those who did not abstain outside of Ramadan is not significantly different from the amount given by either observant or non-observant postdinner dictators in Ramadan. Furthermore, note that the amount given by observant and non-observant dictators who had their evening meal during Ramadan is not statistically different. Therefore, the religious observance of Ramadan in itself does not seem to be strong enough to guide more generous transfers without the interaction with the ritual of 
fasting.

Result 3 Dictators during Ramadan who had their evening meal and dictators outside of Ramadan who did not abstain from any consumption of aliments transfer the same amount of money to recipients. This result is insensitive to whether the dictator in Ramadan is observant or non-observant.

A final result gleaned from Table 3 is that transfers increase with age, which corroborates earlier findings of Hinde and Groebel (1991). In fact, in a recent study, List (2011) collected data from the Center on Philanthropy Panel Study (COPPS) and found that not only charitable giving increases with age, but also that giving as a percentage of the household income increases with age. In conjunction with another finding, whereby giving to various causes is largely unaffected by the state of the economy, the author conjectures that a plausible reason for the increase in giving could be social insurance and/or ensuring a peaceful afterlife (p. $165)$.

\section{Discussion}

Our first main result confirms that the cue of hunger makes one more primal and selfpreserving. However, our second main result highlights that the mode of self-preservation weakens in the presence of a more profound internal cue. Specifically, the interaction between alimentary abstention and religious observance overrides self-preservation and promotes instead generosity in accordance with the principles of Muslim life. This pattern in behavior is parallel to that of normal-weight and obese shoppers as documented in Tom (1983). The author finds that normal-weight shoppers over-purchase when hungry, whereas obese and hungry shoppers exhibit a more constraint behavior. Similar to our first main result, the cue of hunger makes normal-weight shoppers more self-preserving, which leads them to excessive shopping. On the other hand, obese and hungry shoppers are better able to resist tempting purchases (see also Nisbett and Kanouse (1969)) as their profound crusade to lose weight takes precedence over their cue of hunger. In the words of Baumeister, Heatherton, and Tice (1994), "the feeling of hunger ... paradoxically gives them solace, since it tells them they are being successful at avoiding calories" (p. 177).

The two aforementioned results also contribute to the on-going debate on whether prosocial behavior is intuitive (and automatic) or deliberative (and slower). On one hand, Rand, Greene, and Nowak (2012) in their high-impact study, view prosocial behavior (cooperation to be precise) as being governed by a dual-process mechanism that pits a fast and intu- 
itive system favoring prosocial behavior against a slower system of reflection that weighs the available options. Using reaction times to distinguish between intuitive and deliberative responses, they find that in the public-goods games, subjects who contribute less to the public good respond more slowly, whereas faster respondents contribute more towards the provision of the public good. Rand, Greene, and Nowak (2012) interpret these findings as suggesting that intuitive responses are more prosocial. On the other hand, Krajbich, Bartling, Hare, and Fehr (2015) caution against using reaction-time differences to distinguish between response types. Specifically, the authors argue that which response is faster depends critically on the parameters of the decision problem. Similar to the study of Krajbich, Bartling, Hare, and Fehr (2015), we are also skeptical with respect to the conclusions in the study of Rand, Greene, and Nowak (2012). Though our study does not base its findings on reaction times, our results suggest that reflection (i.e. the interaction between alimentary abstention and religious observance that overrides self-preservation) is the culprit behind increased prosocial behavior.

Finally, our third main result indicates that increased prosocial behavior is limited to the critical hours of the fasting ritual, where the religious observance of Ramadan interacts with the ritual of fasting. A plausible explanation may be that the night-time Ramadan hours are less strongly associated with religion and religious activities, such as Zakat. The fact that a moral self can be transiently activated is also demonstrated in the study of Shu, Mazar, Gino, Ariely, and Bazerman (2012), where the authors find that signing at the beginning rather than at the end of a self-report, makes ethics salient, and significantly reduces dishonesty.

\section{Concluding Remarks}

We presented evidence that alimentary abstention is related to lower prosocial behavior outside of a religious observance in accordance with the existing literature. However, during the religious month of Ramadan, where fasting is part of the ritual, observant dictators in the midst of their fast exhibit more prosocial behavior than those who have had their evening meal. It is important to note that increased prosocial giving cannot be attributed to alimentary abstention alone, but may be associated with the fact that alimentary abstention occurs during the time period where religious observance is most salient (and it also happens to coincide with fasting). We also find an increase in transfers with age, which is in line with existing literature (see Hinde and Groebel (1991) and List (2011)).

Ramadan fasting is the longest period of abstention of any major religion and affects a large portion of the world population with likely a substantial economic impact on the world 
economy. Indeed, Campante and Yanagizawa-Drott (2015) find that longer Ramadan fasting has a negative effect on output growth in Muslim countries, but increases the subjective wellbeing of Muslims. The current evidence suggests that the economic impact needs to be better understood in light of prosocial implications. 


\section{References}

Aarøe, Lene, and Michael Bang Petersen. "Hunger Games: Fluctuations in Blood Glucose Levels Influence Support for Social Welfare." Psychological Science 24, 12: (2013) 2550-6.

Andreoni, James, and John H. Miller. "Giving According to GARP: An Experimental Test of the Consistency of Preferences for Altruism." Econometrica 70, 2: (2002) 737-53.

Bardsley, Nicholas. "Dictator Game Giving: Altruism or Artefact?" Experimental Economics 11: (2008) 122-33.

Barro, Robert J., and Rachel M. McCleary. "Religion and Economic Growth Across Countries." American Sociological Review 68: (2003) 760-81.

Baumeister, Roy F., Todd F. Heatherton, and Dianne M. Tice. Losing Control: How and Why People Fail at Self-Regulation. Boston: Academic Press, 1994.

Brañas-Garza, Pablo. "Poverty in Dictator Games: Awakening Solidarity." Journal of Economic Behavior and Organization 60: (2006) 306-20.

—. "Promoting Helping Behavior with Framing in Dictator Games." Journal of Economic Psychology 28: (2007) 477-86.

Burnham, Terence C. "Engineering Altruism: A Theoretical and Experimental Investigation of Anonymity and Gift Giving." Journal of Economic Behavior and Organization 50: (2003) $133-44$.

Campante, Filipe, and David Yanagizawa-Drott. "Does Religion Affect Economic Growth and Happiness? Evidence from Ramadan." Quarterly Journal of Economics 130, 2: (2015) 615-58.

Carpantier, Jean-Francois, and Anastasia Litina. "Dissecting the Act of God: An Exploration of the Effect of Religion on Economic Activity.", 2014. Mimeo.

Clingingsmith, David, Asim Ijaz Khwaja, and Michael Kremer. "Estimating the Impact of the Hajj: Religion and Tolerance in Islam's Global Gathering." Quarterly Journal of Economics 124: (2009) 1133-70.

Danziger, Shai, Jonathan Levav, and Liora Avnaim-Pesso. "Extraneous Factors in Judicial Decisions." Proceedings of the National Academy of Sciences 108, 17: (2011) 6889-92. 
Feltovich, Nick. "Nonparametric Tests of Differences in Medians: Comparison of the Wilcoxon-Mann-Whitney and Robust Rank-Order Tests." Experimental Economics 6, 3: (2003) 273-97.

Forsythe, Robert, Joel L. Horowitz, N.E. Savin, and Martin Sefton. "Fairness in Simple Bargaining Experiments." Games and Economic Behavior 6, 3: (1994) 347-69.

Gailliot, Matthew T. "Energy and Psychology." Global Journal for Research Analysis 4, 7: (2015) 253-5.

Gailliot, Matthew T., and Roy F. Baumeister. "The Physiology of Willpower: Linking Blood Glucose to Self-Control." Personality and Social Psychology Review 11, 4: (2007) 303-27.

Gailliot, Matthew T., Roy F. Baumeister, C. Nathan DeWall, Jon K. Maner, E. Ashby Plant, Dianne M. Tice, Lauren E. Brewer, and Brandon J. Schmeichel. "Self-Control Relies on Glucose as a Limited Energy Source: Willpower is More Than a Metaphor." Journal of Personality and Social Psychology 92: (2007) 325-36.

Haley, Kevin J., and Daniel M.T. Fessler. "Nobody's Watching? Subtle Cues Affecting Generosity in an Anonymous Economic Game." Evolution and Human Behavior 26: (2005) $245-56$.

Harel, Inbal, and Tehila Kogut. "Visceral Needs and Donation Decisions: Do People Identify with Suffering or with Relief?" Journal of Experimental Social Psychology 56: (2015) 249 .

Hinde, Robert A., and Jo Groebel. Cooperation and Prosocial Behavior. Cambridge University Press, 1991.

Karaağaoğlu, Nilgün, and Sevinc Yücecan. "Some Behavioral Changes Observed Among Fasting Subjects, Their Nutritional Habits and Energy Expenditure in Ramadan." International Journal of Food Sciences and Nutrition 51, 2: (2000) 125-34.

Koch, Alexander K., and Hans-Theo Normann. "Giving in Dictator Games: Regard for Others or Regard by Others?" Southern Economic Journal 75: (2008) 223-32.

Krajbich, Ian, Björn Bartling, Todd Hare, and Ernst Fehr. "Rethinking Fast and Slow Based on a Critique of Reaction-Time Reverse Inference." Nature Communications 6: (2015) 7455 EP.

Lambarraa, Fatima, and Gerhard Riener. "On the Norms of Charitable Giving in Islam: A Field Experiment.", 2012. Mimeo. 
List, John A. "On the Interpretation of Giving in Dictator Games." Journal of Political Economy 115: (2007) 482-93.

—. "The Market for Charitable Giving." Journal of Economic Perspectives 25, 2: (2011) 157-80.

McCleary, Rachel M., and Robert J. Barro. "Religion and Economy." Journal of Economic Perspectives 20: (2006) 49-72.

Nisbett, Richard, and David E. Kanouse. "Obesity, Food Deprivation, and Supermarket Shopping Behavior." Journal of Personality and Social Psychology 12, 4: (1969) 289-94.

Rand, David G., Joshua D. Greene, and Martin A. Nowak. "Spontaneous Giving and Calculated Greed." Nature 489: (2012) 427-30.

Shu, Lisa L., Nina Mazar, Francesca Gino, Dan Ariely, and Max H. Bazerman. "Signing at the Beginning Makes Ethics Salient and Decreases Dishonest Self-Reports in Comparison to Signing at the End." Proceedings of the National Academy of Science 109, 38: (2012) $15,197-200$.

Tom, Gail. "Effect of Deprivation on the Grocery Shopping Behavior of Obese and Nonobese Consumers." International Journal of Obesity 7, 4: (1983) 307-11.

Yamagishi, Toshio, and Toko Kiyonari. "The Group as the Container of Generalized Reciprocity." Social Psychology Quarterly, 63, 2: (2000) 116-32.

Ziaee, Vahid, M. Razaei, Zahra Ahmadinejad, H. Shaikh, Rahim Yousefi, L. Yarmohammadi, F. Bozorgi, and Javad Behjati. "The Changes of Metabolic Profile and Weight During Ramadan Fasting." Singapore Medical Journal 47, 5: (2006) 409-14.

Zizzo, Daniel. "Experimenter Demand Effects in Economic Experiments." Experimental Economics 13, 1: (2010) 75-98.

—. "Do Dictator Games Measure Altruism?" In Handbook on the Economics of Philanthropy, Reciprocity and Social Enterprise, edited by Luigino Bruni, and Stefano Zamagni. Northampton MA: Edward Elgar, 2013.

Zizzo, Daniel, and Piers Fleming. "Can Experimental Measures of Sensitivity to Social Pressure Predict Public Good Contribution?" Economics Letters 111: (2011) 239-42. 